\title{
Comparative Evaluation of the Development, Current Situation and Investment Plans of High Speed Railways on National, Regional and International Basis
}

\author{
Mehmet Fatih Altan ${ }^{1, a}$, Mehmet Çağrı Kızıltaşs, ${ }^{1, \text { * }}$ \\ ${ }^{1}$ Department of Civil Engineering, Faculty of Engineering, Istanbul Aydin University, Istanbul, Turkey \\ amehmetaltan@aydin.edu.tr, ${ }^{b}$ cagriuck@gmail.com
}

Received January 5, 2017; accepted March 15, 2017

\begin{abstract}
Various investigations are aimed at creating more modern and efficient automobile and aircraft modes instead of railway passenger transport investments. However, the modal choice has an active role in social trends as well as technical developments. If the social system innovations can be applied and developed to the railway system, HSR can play a major role in the modern transportation system. There are many reasons to promote such a policy. The steel tyred rail system has a great effect. High-speed train technology has proven itself and is loved by the customer. It is available in a wide network of standard railways which can support and feed the HSR network. Railway dismantling reduces energy use and greenhouse gas emissions. As HSR technology (vehicles, train control systems etc) is already well developed, special technological development ideas are more focused on "service design, the removal of traditional obstacles and the strategic development of the HSR network" [1].
\end{abstract}

Keywords: Infrastructure, operation, modal distribution, comparative evaluation, high speed railways.

\section{Introduction}

Transportation is one of the leading service sector nowadays that has a $\mathrm{n}$ affecting and affected relationship with the parameters of economical, technical, social and cultural. The technological improvements that has emerged in 20th century has resulted a wide range of necessity and usage area for each transportation mode. In existing period in 21 st century, it is an obligation to provide intermodal integration on the highest levels beside the most effective and efficient usage of each transportation modes. Because of close and mutual relation between transportation and economy, the economical developments on the scale of regional, national and global cause permenant changes and decision makings on the transportation policies. The developments that has encountered in the world for 40 years has made necessary constituting a more balanced and environmentalist economical perception. Hence there has been directly reflections of this approach to the transportation system. United States of America (USA), European Union (EU), Japan and similar counries have realised the significancy of balanced modal distribution and intermodal integration earlier and started to specify their policies on this frame.

The high-speed railway lines in Europe are in a continuous development process. This development process; it differs according to the countries' urban structures, railway service and technology culture, the centralization

process and political styles. France and Spain have definite and modeled definitions in this area: fewer and far-distance stops, centralization in the capital, such as construction and operation. The ultimate goal of these two countries is; Paris and Madrid, which are their main cities, due to their being the main urban areas. There are also different classifications in HSRs. According to these classifications, the intermediate cities along the HSR corridor were evaluated according to their size and distances to the

\footnotetext{
${ }^{*}$ Corresponding author.

E-mail address : cagriuck@gmail.com (M.Ç. Kızıltaş)
}

https://doi.org/10.29187/jscmt.2018.12 
main station metropolis. The scientific analysis of HSR is traditionally handled in a local, regional, urban, and time-based manner.

For example, "generalized travel cost" can be used as a measure of potential accessibility. However, "travel time" can be used as an accessibility factor in the context of price and departure frequencies. Many French HSR specialists have taken the travel time as their main criteria for their work. In the definition of airline-high-speed railway competition among medium-sized cities, travel time is the most important criterion in terms of mode. The location advantages of cities are measured by their closeness to environmental transport networks rather than proximity to various centers. From this perspective, two phases are important for medium-sized cities on a national basis. The first is the connection of the Environmental Metropolis of the HSR Transportation System and the second is the flow of the passenger flow from the metropolis to the HSR via the transit without passing through the metropolis[1].

The decisions that have presented on White Paper on European Commission in September 2001 that have contained developing of transportation networks on continental phase, establishing the connections to near geographies, increasig the share of railways on modal distribution, making more effective policies on freight transport and rapidly growing on high speed railway investments on the modal, local, regional, national and international phases.

\section{Great Britain}

Eurostar opened in 1994, Belgian SNCB, French SNCF and Eurostar UK Ltd. (EUKL railway) is a joint venture of the companies. The Eurostar has a high share in the passenger market it serves. As of November 2004, it had 68\% of the LondonParis line and 63\% of the London-Brussels line. The trains are 400 meters long, weighing 800 tons and carrying 750 passengers. They reach a maximum speed of $300 \mathrm{~km} / \mathrm{h}$. Modified trains of TGV trains and some Eurostar trains not required on the Canal are used by French national railways on regular TGV flights. In July 2003, Eurostar trains reached a new UK railway speed record of $334.7 \mathrm{~km} / \mathrm{h}$ during the safety test of the Kanal Tunnel Railway Connection[2].

Virgin Trains have made it easier to develop travel times with the development of the Pendolino Sliding Body Trains. Maximum speeds of $200 \mathrm{~km} / \mathrm{h}$ have been reached. Indeed, it is understood that this cost of healing (about $£ 9$ billion) is very high, and that instead of a new line it may be a more appropriate option. The relief of obstruction was the main goal of improvement, but there was a lot of discussion about capacity sharing among many users as work continued and all the indications showed a higher capacity requirement in the south wing of the route.

The Eurostar trains operating along the Eurotunnel between England, France and Belgium are a modified version of the TGV trains and can operate on seven different signaling types with different power systems. There are 18 passenger wagons in the trains. This means it has a significant passenger transport capacity between London and other European cities. A train full of 794 passengers is equivalent to several large planes.

The Eurostar is a trend that connects London to Paris and Brussels. The trains cross the British Channel through the Channel Tunnel. Eurotunnel, the company that builds and operates the Channel Tunnel, is a separate company. The route uses the same high-speed train lines as TGV and Thalys in the French and Belgian sections, and the UK line is in the same standards and is undergoing redevelopment with a new line construction. It is a two-stage project known as CTRL (Canal Tunnel Railway Connection).

$180 \mathrm{~km} / \mathrm{h}$ in 1979, $181.5 \mathrm{~km} / \mathrm{h}$ in 1984, $238 \mathrm{~km} / \mathrm{h}$ in 1987, is a record for diesel trains at this time and still provides a useful service except for Paddington. A project between Channel Tunnel and London was carried out between 1960 and 1975 and unfortunately it faced very serious difficulties due to the economic conditions of the 1973 oil crisis. The British government was concerned about the increased cost of the railway administration with the construction of the Channel Tunnel Railway Network (annual cost estimated at $£ 123$ million to $£ 373$ million) and decided to suspend the project in January 1975. Secondly, and with a thoroughly successful decision, the High Speed 1 (HS1) -High Speed 1 line was partly opened in 2003 and reached its full capacity in 2007, reaching London St.Pancras. As of today, Britain is a very important part of railway transport. However, at the same time, The main example of all the risks and difficulties of the Public-Private Partnership (PPP) and Private Finance Initiative is also presented. When a part of the promised Private Sector support was realized at $£ 2.7$ billion in 1994, until 1998 and 2001, the Government's financial assistance also increased sharply and the total cost of the project exceeded $£ 5$ billion[3].

High-speed railways have a somewhat complicated history in Britain. Under the APT project of the British Railways, speedmaximizing design without the need for expensive new infrastructure was innovative, but the accident that took place in 1981-8284 brought Britain to the point of discouraging this issue. HSR has started to operate at a speed of $200 \mathrm{~km} / \mathrm{h}$ on the Great 
Western Main Line (October 1976) and the East Cost Main Line (since 1978). For over 20 years, the main road of the operation of the British Railway Voyage is taking place.

The Ministry of Environment and Transportation (DER) was formed in 2000, While there is no reference to the new high-speed railway construction in the plan, Time-saving improvements on existing projects and in particular the completion of the CTRL (Channel Tunnel Railway Network) and the modernization of existing lines, especially the West Coast Line (WCML). Indeed, many times the British Railway Policy implements the improvement of the existing line infrastructure on the main route. In 2006, the Eddington Transport Study (Eddington Transport Studies) advocated that British urban centers are closer than Spain and France, and that existing railway services would be sufficient. Eddington predicted that the huge selection of projects could have vague returns and that the HSR option is "the most valuable monetary option for relieving dense corridors." This argument was supported by the British Government White Paper.

\section{Germany}

In Germany, as in Britain, train speeds are limited by infrastructure and railway traffic characteristics, and there is an operating system on the Main Line where passengers and cargo are applied together. Germany High-speed Railway Services entered operation in the 1980s immediately following France. Intercity Express (Intercity Express - ICE) is spreading regularly across all German soil and arriving at high speeds. Against the fact that Germany is Europe's largest economy; It has only two lines that can travel at speeds of $290 \mathrm{~km} / \mathrm{h}$ and above. These are Frankfurt-Cologne and Munich-Nuremburg. The rest of the country's many HSR lines are speeding around $194 \mathrm{~km} / \mathrm{h}[3]$.

These results indicate lower rates compared to the French TGV. While it takes 6 hours from Munich to Berlin, the ParisMarseille TGV line takes about 3 hours at almost the same distance. Germany's high-speed railway experience is rooted, and Europe and the world leader have long been in this position. But with that, we see that in recent years we have lost this acceleration to Spain. This is because they have not succeeded in maintaining the same comfort parameters and improvements in speed values and have hosted HSR accidents in some important disaster. In Germany, ICE (Intercity Express) offers high-speed train service and can be translated as high-speed intercity. Within the country, the lines are more or less north-south-oriented and are located somewhere in the east-west axis. Within the country, the main service routes are headquartered in Berlin-MunichHamburg-Cologne and Frankfurt.

Germany compete with France for speed record breaking, reaching speeds of $346 \mathrm{~km} / \mathrm{h}$ in 1986 and $407 \mathrm{~km} / \mathrm{h}$ in 1988, but the periodic services are usually followed on conventional rails by British Rail speeds. The requirement of crossing over hilly terrain and low sloping sections has resulted in the use of new infrastructure for freight transport and the rising cost of construction in comparison. In addition, the costs were influenced by the high public perception and sensitivity of the German public, which created a more complex and centrist political atmosphere. All this means that construction costs are inevitably three times that of TGV per kilometer. At the same time, due to the more limited effects of the ICE, traffic is also lower compared to TGV and Shinkansen[3].

ICE trains reach a maximum speed of $250 \mathrm{~km} / \mathrm{h}$ in newly constructed sections. The high-speed train line between BerlinHannover was opened in 1998 and in August 2002, a $177 \mathrm{~km}$ cruise line was launched on the new line of Cologne-Rhine / Main. The other lines currently under construction are the Nurnberg-Ingolstadt, Karlsruhe-Offenburg and Cologne-Aachen roads. The ICE has a network of 2,000 km. Only half of this network allows more than $250 \mathrm{~km} / \mathrm{h}$. Although ICE began operating only in 1991, it has made great strides since thenThe first trains have a maximum of 14 passenger wagons with two locomotives and a seating capacity of 723 . The newly developed ICE 2.2 has a performance of $8,000 \mathrm{~kW}$ and reaches a maximum speed of $330 \mathrm{~km} /$ $\mathrm{h}$. The innovation in the design of these new trains is the inclusion of the driving unit on each vagon, which distributes the weight evenly and allows more acceleration. Some of these trains have been constructed so that they can use different power systems for international flights.

ICE Services; (EU) integration area with the services of Copenhagen (Denmark), Zurich (Switzerland), London (England), Paris (France), Vienna (Austria), Amsterdam (Netherlands) and Brussels (Belgium). The high-speed rail service in Germany began in June 1991 when the ICE (Intercity Express) entered the market and opened two lines connecting Hamburg and Munich. The German state railways are operated by DB Fernverkehr, a semi-independent company of Deutsche Bahn.

\section{European Union (EU) -Americas United States (U.S.) Comparison}

In the EU, motorway transit pricing practices are more prevalent and fuel prices are higher than in U.S.A. Fuel prices vary by time and geography, but are generally around twice as much as the U.S. in the EU. Pricing on European Union highways is 
applied in about $12 \%$ to $30 \%$ of the total network lengths according to countries, which is only $1.3 \%$ in U.S.A [4]. In addition, rail subsidies in the EU are generally heavier than in the US, while subsidies in the rail passenger transport are significantly higher in the US, while "indirect taxes" in rail freight transport are higher than in the US Million dollars) are seen to be directed to this area by the government, the provinces and similar institutions. While most of the subsidies are generally directed to rail passenger transport in the EU, almost half of these amounts (18.364 million euros of EUR 38,306 million in 2001) are allocated to the "railway infrastructure" jointly used by both freight and passenger transport. One of the disadvantages of the EU Railway Policies is that "passenger transport" is considered to be much more important than "freight transport" in this sense. In this sense, the share of railways in the passenger transport between cities is $6.25 \%$ in the EU in the US this ratio is only $0.32 \%$. Below on Table 1 is illustrated the enhance of HSR in Europe on related period [4].

Table 1. The Enhance Of High Speed Railways (HSR) In Europe in 1994-2004 Period [4]

\begin{tabular}{|l|l|l|l|l|l|}
\hline Year & France & Germany & Italy & Spain & Europe \\
\hline 1994 & 21.9 & 8.2 & 0.8 & 0.9 & 32.1 \\
\hline 1999 & 32.2 & 10.2 & 4.4 & 1.7 & 52.7 \\
\hline 2004 & 41.5 & 19.6 & 7.9 & 2.8 & 75.9 \\
\hline $\begin{array}{l}\text { Increase Rate\% } \\
(1994-2004)\end{array}$ & $\% 89$ & $\% 139$ & $\% 888$ & $\% 222$ & $\% 136$ \\
\hline $\begin{array}{l}\text { The Share On } \\
\text { European } \\
\text { Traffic (\%) }\end{array}$ & $\% 55$ & $\% 26$ & $\% 10$ & $\% 4$ & - \\
\hline
\end{tabular}

Below on Table 2 is illustrated the modal share change on related cities because of starting to HSR operation [4].

Table 2. Modal Share Changes For Paris-Lyon and Madrid-Seville[4]

\begin{tabular}{|l|l|l|l|l|}
\hline Mode & \multicolumn{3}{|l|}{ Paris-Lyon(\%) } & Madrid-Seville(\%) \\
\hline & Till 1981 & After 1984 & Till 1991 & After 1994 \\
\hline Airway & 31 & 7 & 40 & 13 \\
\hline Railway & 40 & 72 & 16 & 51 \\
\hline Automobile/Bus & 29 & 21 & 44 & 36 \\
\hline
\end{tabular}

Railway routes are limited and there are significant opportunities and workings to improve them for "passenger transport", but the same is not true for "freight transport". The development of rail freight transport in the EU will develop through the technical capabilities of 'multidisciplinary operations' and the joint training of locomotive drivers between countries. Two important topics are coordination and funding sources. Another important threshold is the demand balance between passenger and freight transport, and there are considerable constraints on many points in the EU, especially in urban freight transport. Increasing the line capacity, increasing the quality of the infrastructure, especially the signaling, stands out as a possibility to directly increase the share of railroad freight transport. Another important issue is encouraging rail freight transport and increasing sectoral competitiveness.

Shorter transport distances and longer shorelines are characteristic of the EU compared to U.S.A., while the "product diversity", which is not very different from one another in general in the two geographies, is a title that stands out on a certain scale. The main factor here is the emerging policies of the EU in the sense of rail freight transport and is seen as the most important advantage area. The medium term implications of these policies are that rail freight transport can deliver an acceleration of up to $65 \%$. This is one of the main objectives of the European Commission's 2001 White Paper.

But in all these changes and projections, it is not possible for the EU to reach a $38 \%$ share of the U.S. in freight transport in the mid-term.

The European Union has an advanced rail network that is longer than the United States (the European Union rail network $215.900 \mathrm{~km}$, the United States $203.600 \mathrm{~km}$ ). However, in the EU, it is important to ensure that uninterrupted transport (border crossings, technical and administrative differences), infrastructure is shared by passengers and freight trains, freight trains are operated at lower speeds and passenger trains are entitled to pass, and in case of disruption they are faced with great danger. As a result, railway freight transport efficiency in Europe is much lower than in North America, where most of the railway lines are 
overloaded. According to some estimates, the cost per ton / $\mathrm{km}$ in the EU is 8 cents, while in the United States it is close to 1 cent. Due to the contribution of some lines to the overhead of the development of rail freight transport, regulation 913/2010 in the EU has begun to create rail freight corridors within the EU and obligatory for member states to complete the work until the end of 2015[5]. Considering this example and approach, it is considered that in order to be able to carry an efficient rail freight transport, it is necessary to create corridors in the form of 'freight-specific or freight priority lines' throughout the country.

\section{Investment Cost}

The cost per kilometer is $\$ 4$ million, and the most expensive French investments are currently in the $\$ 10-15$ million range, with Italy at \$ 25 million / km and the United Kingdom at \$ 74 million / km (Channel Tunnel Railway Network First Phasic) costs[6]. Table 3 below shows the comparative costs of producing HSR countries.

Table 3. High Speed Railway (HSR) Construction Costs [6]

\begin{tabular}{|c|c|}
\hline Country & $\begin{array}{c}\text { US \$ } \\
\text { millions } \\
\text { per km }\end{array}$ \\
\hline France and Spain & 10 \\
\hline $\begin{array}{c}\text { Belgium and } \\
\text { Germany }\end{array}$ & 15 \\
\hline Italy & 25 \\
\hline Netherlands & 53 \\
\hline Britain & 74 \\
\hline Taiwan & 37 \\
\hline South Korea & 37 \\
\hline
\end{tabular}

\section{Results}

Preference of the method of more effective and more efficient usage of existing transportation systems rather than constructing new roads for enhancing the network capacity as a general approach for transportation problems solution tht is more important fort he future of the urban. Enhancing of the efficiency studies are included to short term applications in transportation engineering. The short term studies of the units that are responsible on traffic can be stated on four main topic that are geometrical regulations, signalling applications, awareness studies and traffic enforcement implementations. Traffic enforcement studies have an important role on increasing the road safety.

Worldwide, high-speed trains can be operated at an average speed of $200 \mathrm{~km} / \mathrm{h}$ over the existing infrastructure. Above this, speeding up is possible in some countries, and much higher speeds can be reached in trial phase. In the operation of high-speed railways, ceiling speeds are $250-275 \mathrm{~km} / \mathrm{h}$, which can be picked up by countries such as Japan, China, Spain and France[7]. While Japan and France have been able to strengthen their sectoral experiences with their technological developments for many years, Spain and China have been able to make important leaps, even though this service sector is much newer. While Italy, Germany and the UK were staying at certain speeds, Germany was able to construct a high-speed railway line at a significant level of country and territory.

Spain, on the other hand, has surpassed France and Japan in terms of the length of the line that it has reached with investments in recent years. Germany continues to spread the length of the line, which is spread to a significant part of its surface area, with regular investments, and regularly improves the infrastructure and service parameters. As a result, Germany is in the 3rd place on the sectoral basis in Europe and it seems that this country is trying to increase integration with the high speed railway investments common in countries such as Belgium, Switzerland, Netherlands, France and Italy. Britain and Italy, on the other hand, have entered a serious pause after the industry has made an early and rapid entry and it seems that Italy's high-speed railway construction plans have been on the agenda again in recent years.

High-speed railway investments will continue in this period in other Far East countries, especially in Taiwan and South Korea, with the participation of new countries in the high-speed railway sector. China considers it necessary to disseminate these services to all of its geography within a short period of time and then develop linkages with neighboring countries in parallel with its priority and economic needs and capacity requirements. In the case of Spain; it is also expected that China will invest a considerable amount of high-speed railway with great acceleration. It is understood that both countries have prioritized 
investments in this sector in the sense of national integration, and it is seen that the regional integration phase is already on the agenda.

Following the success of the high-speed railways in Japan, France and Germany, many new HSR network plans are in place. The new 7,000 km HSR line is in the construction of Far East Countries such as South Korea, China and Taiwan while the other side is constructing a new 2,000 km HSR line in countries such as Russia, Germany, France and the UK[7]. High-speed railways have reached a share of approximately $25 \%$ on passenger transport across the European Union. In Asia, Turkey, South Korea, Taiwan and China, the United States, the United States, the new HSR Services are in charge. Especially China; The HSR has received first investments in its investments[7]. In Turkey, a rapidly and effective establishment period has been realized on high speed railway (HSR) transportation modes, intraurban-inter urban and interregional projects railway system projects particularly Marmaray have been realized, the load on the highway transportation mode has been transferred to railway and airway transportation modes comparatively by existing transportation investments. On this context, human focused approach, considering the environmental factors and improving a sustainable understanding will be very signicifant on the investment period.

High-speed railways are a technical innovation and have been unveiled with many developments integrated on 'traditional railways' in order to create a faster and more efficient mode of transport. However, in reality there is a real sense that HSR is often operated on the same logic as traditional railroads, in other words, older services are functionalized by wearing a new, faster view. This booster approach has been successful in many sectors. However, an innovative search of the socio-technical system in the social wing can reveal the development of more attractive and efficient services to the day's transport demands through integrated HSR networks.

\section{References}

1. Railway Gazette International, October 2009. 'The Sustainable Railway', http://archiv.railwaygazette.com/railwaygazette-international.html?tx_dc5archive, 63-4.

2. Takagi, Ryo. 2005. High Speed Railways: The Last Ten Years, 40 Years of High Speed Railways. Japan Railway \& Transport Review. No. 40 (pp.4-7).

3. Ebeling, Klaus. 2005. High Speed Railways in Germany: 40 Years of High Speed Railways. Japan Railway \& Transport Review. No. 40 (pp.36-45).

4. Vassallo, Jose., Fagan, Mark., 2006. Nature or nurture: why do railroads carry greater freight share in the United States than in Europe? Transportation. (2007) 34:177-193.

5. NERA. 2004. Study of the Financing of and Public Budget Contribution to Railways, Final Report for European Commission DG TREN, London. The Transport Politic. 2012. Should the U.S. spend \$1 trillion on new infrastructure? http://www.thetransportpolitic.com/ available: (17/07/2012).

6. T.C. Ulaştırma, Denizcilik ve Haberleşme Bakanlığı 11. Ulaştırma, Denizcilik ve Haberleşme Şurası Sektör Raporu. 2013. http://www.ulastirmasurasi.org/tr/main_page.html available: (11/03/2013). 